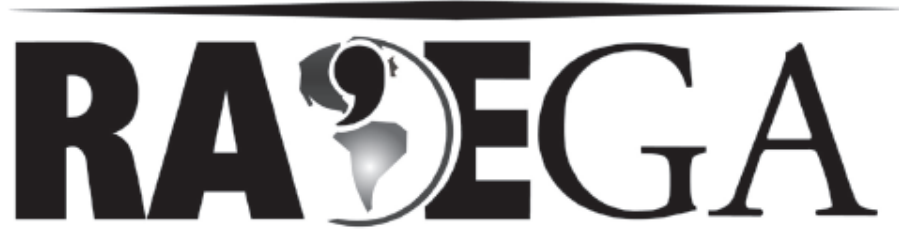

O ESPAÇO GEOGRÁFICO EM ANÁLISE

\title{
O ESPAÇO COMO CATEGORIA DE ANÁLISE SÓCIO- CULTURAL: UM DIÁLOGO ENTRE A SOCIOLOGIA CULTURAL E A GEOGRAFIA
}

THE SPACE AS CATEGORY OF SOCIO-CULTURAL ANALYSIS: A DIALOGUE BETWEEN CULTURAL SOCIOLOGY AND GEOGRAPHY

\section{EL ESPACIO COMO CATEGORÍA SOCIO-CULTURALES DE ANÁLISIS: UM DIÁLOGO ENTRE SOCIOLOGÍA DE LA CULTURA Y LA GEOGRAFIA}

\section{Cinthia Maria de Sena Abrahão ${ }^{1}$}

\section{RESUMO}

Este ensaio busca estabelecer um diálogo interdisciplinar. Geografia e Sociologia se entrelaçam e buscam no espaço os argumentos articuladores da vida social. Tem a cidade como recorte central e recorre ao aporte teórico oferecido por autores como Milton Santos, David Harvey, George Simmel e Jesús Martin Barbero.

Palavras-chave: espaço; sociabilidade; cidade; cultura.

\section{ABSTRACT}

This essay seeks to establish an interdisciplinary dialogue. Geography and Sociology entwines and seek space in articulating the arguments of social life. The city is the focus and resorts to theoretical offered by authors such as Milton Santos, David Harvey, George Simmel and Jesús Martin Barbero.

Key-words: space; sociability; city; culture.

\footnotetext{
${ }^{1}$ Graduada em Economia pela Universidade Federal de Uberlândia, Mestre em História Econômica pela Universidade de São Paulo, Doutoranda em Geografia na Universidade Federal do Paraná, Professora na area de Gestão Empresarial na Universidade Federal do Paraná - Setor Litoral.

E-mail: cisab@ufpr.br; cisena@terra.com.br.
} 
O MAPA

Olho o mapa da cidade

Como quem examinasse

A anatomia de um corpo...

(É nem que fosse o meu corpo!)

Sinto uma dor infinita

Das ruas de Porto Alegre

Onde jamais passarei...

Há tanta esquina esquisita,

Tanta nuança de paredes,

Há tanta moça bonita

Nas ruas que não andei

( $E$ há uma rua encantada

Que nem em sonhos sonhei...)

Quando eu for, um dia desses,

Poeira ou folha levada

No vento da madrugada,

Serei um pouco do nada

Invisível, delicioso

Que faz com que o teu ar

Pareça mais um olhar,

Suave mistério amoroso,

Cidade de meu andar

(Deste já tão longo andar!)

E talvez de meu repouso...

Mário Quintana - Apontamentos de História Sobrenatural, 2005.

A dimensão espacial dos fenômenos tem sido revisitada por várias ciências, a partir das quais o espaço emerge como algo dotado de vida e de sentido, portanto, de contradições inerentes à condição humana. Nestas abordagens a idéia geométrica de tábua rasa da história torna-se destituída de sentido e conexidade. Induz ao pensamento complexo que possibilita a reunião, a contextualização que a racionalidade moderna perdeu ao longo do tempo. 
É justamente através da complexidade desta categoria, espaço, que procuramos neste ensaio compreender e abordar a cidade contemporânea. Para tanto, buscamos um diálogo com autores do campo da Sociologia e da Geografia, considerando que são estes os ambientes de investigação que mais profundamente têm se dedicado a compreendê-lo.

O intuito mais explícito que move esta digressão é perceber a cidade enquanto elemento que expressa racionalidade, ladeada pelo emaranhado complexo e contraditório que representa a existência humana. Pensada historicamente a cidade se nos apresenta como aglutinador dos processos sócio-culturais. Em destaque buscamos relevar algumas das marcas históricas que o espaço da cidade latino-americana, em especial a brasileira, contém e expressa.

\section{Um diálogo entre tempo e espaço: a cidade como espaço e o espaço da cidade}

Refletindo sobre a "cegueira do conhecimento", Morin (2000a) demonstra que o conhecimento comporta tanto o erro, como a ilusão. Em busca da eliminação de ambos, erro e ilusão, a razão foi alçada ao primeiro plano da ciência. No entanto, a racionalidade se transformou em racionalização, entendida como sistema lógico, perfeito e irrefutável. Neste sentido, os elementos da percepção, da afetividade, portanto da subjetividade humana, que se expressam na cultura, foram subjugados, tornados desimportantes pela ciência moderna. Perverteu-se assim a busca do conhecimento em arrogância, distanciada da compreensão efetiva da sociedade humana.

Conforme Mathews (2004), a modernidade trouxe à Geografia a percepção da necessária separação entre o mundo humano, em seus aspectos sociocultural e biofísico. Porém, segundo este autor, a questão ambiental contemporaneamente recolocou a necessária interrelação entre os dois campos. Dentro deste contexto, quando se explicita a "necessidade de um pensamento complexo" (Morin, 2000b) e que se percebe um novo percurso da 
Geografia em busca da síntese científica entre o físico e o humano é que também se reforça, a nosso ver, a importância de refletir sobre os espaços de conviver dos homens, em especial as cidades. Tal objeto, no entanto, torna imperativa a fundamentação teórica interdisciplinar, especialmente no que tange à compreensão dos fenômenos sociopolíticos e econômicos que 0 caracterizam.

Nesta perspectiva, Milton Santos buscou no objeto da Geografia o desvelar desta mesma teia que entretece natureza humana e natureza não humana, elegendo o espaço enquanto conceito centralizador. Este aparece como resultante do casamento entre sociedade e paisagem. Configura-se assim um par dialético, na medida em que se complementam e se opõem (SANTOS, 1988, p. 26).

A abordagem do espaço passa pela perspectiva de conduzir o pesquisador ao processo de renúncia à visão unidimensional, na medida em que a realidade é por natureza complexa e multifacetada. "Nas condições novas, aumenta a possibilidade de ajudar as ciências afins a progredir de fora para dentro com a contribuição de matérias vizinhas" (SANTOS, 2008, p.136).

Se tomarmos como ponto de partida o conceito de espaço, bem como aqueles que remetem especificamente ao composto real que a cidade representa, em sua acepção contemporânea, tornar-se-á evidente a necessidade de abordar elementos de análise que foram dicotomizados pela ciência moderna. Neste sentido, em Georg Simmel² (Apud Tedesco, 2007, p. 57) há um contraponto ao mecanismo totalitário desta, revelando ser possível renunciar aos mitos da integração e da legalidade científica no processo de construção do conhecimento. Simmel percebe a interligação dos fenômenos e das idéias, explicitando assim uma teia complexa e intersubjetiva característica das sociedades humanas.

O conceito de espaço representa em Santos (1988) a busca de uma nova síntese no objeto da pesquisa geográfica. Através dele o pesquisador é levado a pensar o mundo a partir da consciência de que o mesmo é representação do humano, portanto, fruto de sua existência. "O espaço é

\footnotetext{
${ }^{2}$ Vale destacar que Simmel trabalhava com a idéia de espaço geométrico como objeto da Geografia.
} 
resultado da ação dos homens sobre o próprio espaço, intermediado pelos objetos, naturais e artificiais" (SANTOS, 1988, p. 25). É também incorporador das marcas temporais da história humana, e, portanto, das expressões culturais de uma sociedade.

Para Simmel (1993, p.21) a sociedade é uma realidade erigida sobre o espaço e o tempo, fruto de constantes e múltiplas interações humanas na lógica de uns contra outros, uns pelos outros e/ou uns com os outros. Neste sentido, a perspectiva relacional interconecta perspectivas aparentemente tão distantes ${ }^{3}$, indivíduo/sociedade, homem/natureza.

As duas categorias essenciais da existência humana, o tempo e o espaço, encontram-se recuperadas neste campo. A metáfora do tempo, vinculada à idéia de progresso, torna impositiva a convicção de que 'caminhamos para frente'. Incorpora, desta forma, a premissa do 'destino manifesto' da história humana presente na modernidade. O mesmo projeto moderno trouxe consigo uma forte perspectiva de organização do espaço das cidades. Neste ambiente ocorre uma espécie de naturalização do descolamento da dimensão espacial em relação aos processos sociais (HARVEY, 1992). O que significa tratar o espaço como elemento manipulável, capaz de ser moldado à luz de uma racionalidade técnica e objetiva.

Contudo, a ordem invisível que cria os laços e organiza o conjunto de indivíduos numa espécie de 'todo', mas cuja imanência é por natureza não estática, representa a própria sociedade para Norbert Elias (1994). Em seu nível de mais alta complexidade, a vida nas grandes cidades expressa o limite deste entrelace, numa forma tipo, que combina a percepção de isolamento do indivíduo mediante o adensamento físico de pessoas. Também em Simmel (2009, p. 583) esta questão está colocada, revelando a cidade, especialmente a grande cidade típica da modernidade, como uma forma que possibilita a aproximação de um quantun significativo de pessoas, ao mesmo tempo em que promove a proliferação dos mecanismos de afastamento que a tornam destituída de alma.

\footnotetext{
${ }^{3}$ Segundo Costa (1999), o papel do indivíduo, os processos de interação, a distinção entre forma e conteúdo, entre vida e forma, unidade e mudança social são temas e categorias centrais do pensamento simmeliano. Este autor elaborou um estilo de pensar o par indivíduo/sociedade menos dicotômica e mais interativa.
} 
De acordo com Benevolo (1991, p. 13) um dos sentidos da cidade é configurar a representação da situação física da sociedade. As características do espaço que se conformam no organismo da cidade tendem a subverter 0 tempo e persistir, em geral, mais que a própria forma de organização da sociedade. Neste sentido, a cidade configura o objeto mais privilegiado de análise espacial no sentido proposto por Santos (1988), porque carrega as temporalidades distintas em suas marcas físicas, através dos resquícios de formas distintas de organização social. A partir de Elias (1994, p. 36), pode-se afirmar que ela congrega uma rede de relações que não se circunscreve a uma teia de representações espaciais, mas temporais e espaciais.

A cidade representa um conjunto de artefatos artificiais, introduzidos pelo homem em uma porção do ambiente natural. Constitui também a expressão cultural de uma organização social, uma organização de experiências (BENÉVOLO, 1991). Pode-se acrescentar ainda, que congrega a expressão da ordem econômica e do sistema político compondo múltiplos fatores, o que permite configurar o que se entende por sua dimensão territorial.

Em Benévolo (1991), a historicidade das cidades européias explicitam os fundamentos temporais da construção de teorias da organização do espaço, do ordenamento do espaço vivido. Adveio deste processo o planejamento urbano como ferramenta organizacional do controle social. Vale dizer que há um estado distinto, portanto, um conteúdo distinto ${ }^{4}$, de acordo com o qual os indivíduos se portam uns em relação aos outros nas cidades grandes. Este estado é o de autopreservação e reserva, afastamento dos indivíduos em relação uns aos outros, porque há uma desconfiança natural que se estabelece nas relações (SIMMEL, 2009, p. 580).

Ao mesmo tempo, na concepção contemporânea da geografia cultural se explicitam os elementos subjetivos da relação indivíduo/espaço. O mundo vivido, experimentado pelo sujeito cotidianamente, do bairro, da vizinhança, do lugar expressam um "mundo-vivido cultural" (KOZEL, 2007, p.119). Há uma intimidade entre indivíduo socialmente definido e o espaço onde vive que não

\footnotetext{
${ }^{4}$ As interações que promovem a unidade social, mesmo diante da fragmentação e da renovação mas que permitem a sobrevivência da sociedade, constituem segundo Simmel o objeto que requer uma abordagem específica. Para ele, construir esta abordagem seria exatamente o papel da Sociologia enquanto ciência social, que se distingue da História ou da Antropologia (COSTA, 1999, p. 301).
} 
se pode interpretar exclusivamente a partir dos instrumentos convencionais da leitura geográfica do espaço.

Para Simmel (2009), tanto o indivíduo, quanto a sociedade assumem um segundo plano em relação à interação geradora constitutiva desses dois pólos. O vínculo social, neste sentido, emerge como síntese desta relação entre o indivíduo formador do conjunto social, e a formatação que este conjunto produz no indivíduo. Neste sentido, mecanismos de afastamento, a exemplo da antipatia que é desagregadora, também são elementos de sociabilização, já que persiste uma busca de espaços de particularização. Isto se torna evidente na medida em que por meio do vínculo social o indivíduo se filia ao que Simmel (2009, p. 582) chama de "esquisitices urbanas" (contemporaneamente, poderíamos traduzi-las nos guetos, nas gangues, nas tribos tipicamente urbanas). Estas, por sua vez, são constituídas enquanto espaços de diferenciação e autoreconhecimento.

Ao se referir à cidade, Elias (1994) fala de um espaço em que a liberdade de fato é restritiva, limitada, porém nunca nula. No mesmo tom, Canclini (2003) aponta a violência e a insegurança como indutores da intimidade doméstica traduzida em encontros confiáveis, na seleção das formas de sociabilidade. Contemporaneamente, o que se verifica é uma redução de mobilidade, em especial nas grandes cidades, onde os grupos populares saem pouco dos espaços periféricos ou centrais. Por outro lado, os setores médios sobem muros e reforçam janelas promovendo uma forma mais individualizada de isolamento.

Nesta dialética expressa no corpo da cidade há um processo que atrai e repulsa, mas que na análise microscópica pode explicitar seus laços invisíveis. Como ...

em Cloé, cidade grande, as pessoas que passam pelas ruas não se reconhecem. Quando se vêem, imaginam mil coisas a respeito umas das outras, os encontros que poderiam ocorrer entre elas, as conversas, as surpresas, as carícias, as mordidas. Mas ninguém se cumprimenta, os olhares se cruzam por um segundo e depois se desviam, procuram outros olhares, não se fixam (CALVINO, 1997, p. $51)$. 


\section{Urbanidade ou urbanidades na América Latina}

Velho (1986, p. 49) reflete sobre a vida urbana pensando-a como palco no qual a divisão social do trabalho e as diversas formas de sociabilidade propiciam a densificação, mas também a fragmentação em muitos "mundos", que coexistem com ou sem fronteiras espaciais tangenciáveis. É fato que os primeiros povos que construíram e viveram em cidades estavam no Oriente. No entanto, a civilização urbana assumiu no ocidente uma espécie de força centrífuga que levou suas influências para o novo continente da América, desde o processo de colonização no século XVI.

As raízes desta urbanidade moderna estão no baixo medievo europeu, que Le Goff (1992) chamou de apogeu da cidade medieval, quando foi germinada a civilização urbana que se tornou hegemônica. Na França do século XIII ocorreu, segundo este autor, a primeira tomada de consciência urbana, suplantando a lógica da cidade amorfa, do lugar sem identidade, oriundo da ação de diversos grupos que buscavam se proteger dos senhores (LE GOFF, 1992, p.3). Esta cidade, a medieval, originariamente em muito se distinguia da cidade antiga fundada com o propósito estadista, político e militar.

A cidade medieval, em função de seu crescimento orgânico e da capacidade de gestar a classe social que revolucionaria o modo de produção, a burguesia, nos oferece alguns fundamentos instigantes para a reflexão sobre a cidade moderna.

Em primeira instância, vale observar que grande parte dos moradores da cidade medieval estavam vinculados ao rural, camponeses por excelência (LE GOFF, 1992). O que em si parece uma redundância nos traz elementos para pensar fora da dicotomia moderna que separa de forma inexorável urbano e rural, como dois mundos em oposição.

Em geral, no período medieval, a curta distância era a característica dos fluxos migratórios. De acordo com Le Goff (1992, p. 10), as cidades francesas do Séc. XIII eram semi-rurais. Mas, estes fluxos propiciaram que, no nível dos homens, da cotidianidade das relações, ocorresse a interpenetração do rural 
com o urbano. É nesta instância que foi vivenciada a redefinição e permanência dos hábitos e valores.

Redefinição esta que não seguiu o ritmo de mudanças dos fatos econômicos e sociais. Assim, Le Goff torna o popular "o lugar metodológico a partir do qual se deve reler a história não enquanto história da cultura, mas enquanto história cultural" (MARTIN-BARBERO, 2001, p. 104).

Da mesma forma, em Simmel também fica explicitado que o conhecimento requer esta análise do microcosmo da sociedade. $O$ conhecimento não se circunscreve ao lógico, existe uma gama de sentimentos e sensações, de coisas não lógicas e imprevisíveis que estão presentes quando um sujeito conhece e se relaciona com outro (COSTA, 1999, p. 300). O modo de vida urbano cultivado tornou cada vez mais profundo este conjunto de interações, ainda que a elaboração científica do conhecimento tenha resistido a compreendê-lo em todo o seu significado.

A história das cidades modernas, oriundas do Velho Mundo, teve ressonância muito grande nos países que se organizaram e/ou transitaram forçosamente rumo à modernidade. As cidades deste 'novo' mundo explicitam as heranças de dominação, que, por sua vez, foram determinantes na formatação das características específicas de sua inserção no capitalismo. De tal forma que sua expressão territorial combina um mosaico de elementos culturais.

Vista contemporaneamente, a cidade brasileira em geral reflete características vividas pelas cidades européias do século XIX, do período entre-guerras e aquelas vivenciadas hoje. Coexistem problemas e soluções de etapas distintas da organização da cidade moderna, tal como foi vivenciado no continente europeu. Mas, esta combinação, por sua vez, torna o processo de constituição, organização e o estabelecimento das formas de controle das cidades muito específico.

Um primeiro elemento de especificidade que se sobressai neste espaçocontinente está relacionado à própria estrutura física da cidade. A geometria da cidade brasileira promove o sentido do conceito de periferia. A palavra periferia, por sua vez, assume conotação distinta no contexto histórico latino-americano. 
Seu sentido é muito mais denso, compreendendo os aspectos político, econômico e social. Neste sentido, também cultural.

As discussões latino-americanas que propiciaram a elaboração da teoria da dependência trouxeram à tona o conceito de periferia, que foi transposto para o organismo da cidade. Isto se deu, principalmente, a partir dos anos de 1960-1970, e no caso brasileiro vinculado, de forma contundente, ao processo de metropolização que marcou a região sudeste do país. Nesta abordagem, a periferia consiste no espaço de exclusão por excelência, de acesso precarizado aos direitos de pertencimento à cidade.

Em 'O Direito à Cidade', Lefebvre (1991) aborda o surgimento deste novo agente social que é o morador da periferia urbano-industrial. Na medida em que a industrialização, e, no sentido mais amplo, o modo de produção capitalista transformam o espaço em mercadoria, em produto, aos pobres ela se torna cada vez menos acessível. A questão da periferização do espaço urbano e sua faceta de normalidade é facilmente evidenciável para os analistas da realidade brasileira. Tanto mais quando o foco está nas cidades médias e nas regiões metropolitanas. Conforme Felício e Anjos (2007, p. 186), a segregação social assume uma condição de processo, valorizando "a idéia de tendência introduzida na geografia urbana por Castells".

Elias e Scotson (2000) revelam que a percepção das diferenças entre grupos sociais, bem como a disputa de poder inerente ao processo de estabelecimento da superioridade constituem elementos marcantes para o desenvolvimento das periferias, mesmo em pequenas comunidades. São variados os elementos subjetivos expressos na construção da auto-imagem dos grupos. Tais elementos se combinam na definição da idéia de 'superioridade'. Em Simmel (1998), o desejo da individualidade aparece marcado pelo desejo de distinção, de diferenciação do sujeito.

Canclini (2003) lança luzes sobre as ideologias urbanas produzidas a partir do cruzamento de um conjunto de forças da modernidade. Evidencia ainda que a rígida separação cultural entre um 'mundo rural', arcaico, e o 'mundo urbano', moderno, não condiz com o composto sócio-cultural real. De tal forma, que compreender a cidade contemporânea em uma perspectiva 
histórica, capaz de expressar as marcas profundas no espaço e nas relações sociais do urbano latino-americano e brasileiro constitui um desafio que exige a superação da abordagem dicotômica.

Pode-se dizer, conforme Durham (2004, p. 379), que condições de vida semelhantes dêem origem a características culturais próprias, que por sua vez, podem ser vistas sempre que as mesmas condições se reproduzem. Neste sentido, compreendemos a complexidade e a riqueza possível de serem percebidas a partir da leitura das periferias das cidades, na medida em que potencialmente são reveladoras dos novos elementos culturais e de seus laços com o ambiente rural, seja física ou culturalmente.

Contemplar as distintas porções da cidade reside em elucidar a perspectiva do vivido, des-cobrir as dimensões submersas na racionalidade do planejamento urbano, o que na América Latina é reiteradamente subvertido pelo desequilíbrio do crescimento. Desvelando assim as categorias subjetivas, entre o percebido e o vivido.

Em Bersabéia, transmite-se a seguinte crença: que suspensa no céu exista uma outra Bersabéia, onde gravitam as virtudes e os sentimentos mais elevados da cidade, e que, se a Bersabéia terrena tomar a celeste como modelo, elas se tornarão uma única cidade. A imagem que a tradição divulga é de uma cidade de ouro maciço, com tarraxas de prata e portas de diamante, uma cidade-jóia, repleta de entalhes e engastes, que supremas e laboriosas pesquisas, aplicadas a matérias de supremo valor podem produzir. Fiéis a essa crença, os habitantes de Bersabéia cultuam tudo o que lhes evoca a cidade celeste ...

Também crêem, esses habitantes, que existe uma outra Bersabéia no subterrâneo, receptáculo de tudo o que lhes ocorre de desprezível e indigno, eles zelam constantemente para eliminar da Bersabéia emersa qualquer ligação ou semelhança com a gêmea do subsolo (CALVINO, 1997, p. 103).

\section{Civilização, periferização e espaços populares na cidade brasileira}

Se um homem da atual sociedade civilizada ocidental fosse, de repente, transportado para uma época remota de sua própria sociedade, tal como o período medievo-feudal, descobriria nele muito do que julga "incivilizado" em outras sociedades modernas. Sua reação em pouco diferiria da que nele é despertada no presente pelo comportamento de pessoas que vivem em sociedades feudais fora do Mundo Ocidental. Dependendo de sua situação e inclinações, sentir- 
se-ia atraído pela vida mais desregrada, mais descontraída e aventurosa das classes superiores desta sociedade ou repelido pelos costumes "bárbaros", pela pobreza e rudeza que nele encontraria. E como quer que entendesse sua própria "civilização", ele concluiria, da maneira a mais inequívoca, que a sociedade existente nesses tempos pretéritos da história ocidental não era "civilizada" no mesmo sentido e no mesmo grau que a sociedade ocidental moderna (ELIAS, 1994, p. 13).

Nos termos de Elias (1994) cabe sempre a indagação sobre o grau de "civilização" da sociedade brasileira, construída a partir da herança européia. O caso brasileiro deve ser situado, antes de tudo, a partir de seu passado colonial, gerador do "mundo latino-americano". Desde os aglomerados urbanos no período colonial, obviamente neste momento com maior vigor, foi se conformando a influência do aparato jurídico na definição sócio-espacial das cidades brasileiras. Da mesma forma, os hábitos e formas de expressão cultural tornam-se evidências de construções sócio-históricas específicas, na combinação tempo-espaço.

A estrutura escravista em seu auge e declínio deixou marcas importantes nas cidades brasileiras. Villaça [Apud Felício e Anjos, 2007, p. 187] relaciona o fim da escravidão com o surgimento dos subúrbios. Duas ordens de fatores estão relacionadas a este processo originário de segregação. A primeira está relacionada à legalização do latifúndio. Enquanto a segunda se refere a negação do trabalho enquanto valor cultural na sociedade escravista.

A periodização da expansão urbana e do avanço da periferia no Brasil merece destaque. Felício e Anjos (2007, p. 188-190) definem esta periodização a partir dos programas governamentais. Conforme estes autores, teria havido uma primeira fase de invasão dos centros urbanos por atividades comerciais e industriais na segunda metade do século XVIII. Nesta, pouco havia de diferenciação classista, dado que a estratificação social era regida pela propriedade da terra. Na virada do século XIX para o XX, os problemas de saúde pública assolaram os maiores núcleos urbanos do país.

Nos anos 1920 e 1930, surgiram as vilas operárias como uma realidade própria das cidades que viviam a expansão industrial. As elites urbanas

\footnotetext{
${ }^{5}$ Vale dizer que o conceito de civilização, como bem explica Elias (1994, p. 24) não tem caráter único dentro da Europa. Para os franceses e ingleses, o termo é uma referência aos fatos políticos ou econômicos, religiosos ou técnicos, morais ou sociais. Para os alemães refere-se a fatos intelectuais, artísticos e religiosos.
} 
brasileiras habitaram o centro das cidades até a década de 1950. Somente a partir de 1960 teve início a evasão da área central, em função da violência e das contradições nela expressas. Em contraponto, desde o final da segunda guerra até os anos 1960, não haviam sido estabelecidas políticas voltadas para a questão da habitação urbana no Brasil (FELÍcIO e ANJOS, 2007, p. 188).

A idéia de que a "a sobriedade da forma devia moldar um novo homem, trazer a civilização" proliferou entre políticos, empresários e a elite profissional do urbanismo (FELíCIO e ANJOS, 2007, p. 190). A influência do urbanismo modernista de Le Corbusier ${ }^{6}$ demonstrava sua força na formação das mentalidades e na prática do planejamento. A partir desta perspectiva desenvolveu-se e consolidou-se uma relação simbiótica entre a lógica da acumulação de capital e a ação do poder público, tendo como conseqüência o processo de expansão da exclusão residencial.

A rapidez das transformações promoveu de forma ainda mais violenta o mecanismo da sociodinâmica da estigmatização, aquela segunda a qual são definidos os estabelecidos e os outsiders (ELIAS e SCOTSON, 2000). Os outsiders representam uma condição social e também espacial, na medida em que a dinâmica excludente da formação dos bairros populares nas cidades brasileiras reproduz formas seculares de segregação e definição de estigmas.

A proliferação da periferia, seu padrão de construção, baseado na autoconstrução familiar e na ausência, bem como a insuficiência das separações formais e funcionais do espaço do trabalho e do lazer constituem marcas da inserção da sociedade brasileira no contexto da civilização ocidental. Neste sentido, há uma dotação de significado cultural para este espaço configurado como periferia, cuja expressão requer que seja superada a visão dicotomizadora entre cultura dominante e dominada (MARTINBARBERO, 2001).

Como Calvino (1997, p. 59) podemos dizer que,

... se devo explicar como o espírito de Olívia tende para um vida livre e um alto grau de civilização, falarei de mulheres que navegam de noite cantando em canoas iluminadas entre as margens de um estuário verde; mas isso serve apenas para recordar que, nos

\footnotetext{
${ }^{6} \mathrm{O}$ arquiteto e urbanista Charles-Edouard Jeanneret-Gris, conhecido por Le Corbusier, foi um ícone do urbanismo moderno e talvez o mais importante difusor de seus princípios pelo mundo.
} 
subúrbios em que homens e mulheres desembarcam todas as noites como fileiras de sonâmbulos, sempre existe quem começa a gargalhar na escuridão, dá vazão às piadas e aos sarcasmos.

A multiplicidade das identidades culturais se manifestam neste ambiente contraditório da cidade. Harvey (2005) em referência a Robert Park apresenta o ambiente urbano como sendo aquele em que a humanidade pode vivenciar a vida intelectual. Releva, no entanto, que a cidade representa o mundo criado, mas também o mundo no qual se está "condenado" a viver. Neste sentido, a cidade brasileira representa um caldeirão de situações históricas que remetem a um tipo especial e contraditório de civilização (ELIAS, 1994)

A cidade se nos apresenta como criatura e criadora, sendo capaz de expressar, através das relações espacializadas, os vínculos profundos que remetem à essência dos que a habitam. Nela as formas de sociabilidade estão no tempo e no espaço, traduzidas em formas de cooperação e conflito, que se reproduzem, se consolidam, vivenciam rupturas e voltam a se tornar permanências (SIMMEL, 1993).

A partir dos anos 1960, segundo Martin-Barbero (2001, p. 280), a cultura urbana latino-americana foi tomada pela influência de uma indústria cultural, que passou a transpor modelos transnacionais. O processo de sedução desencadeado pelo estímulo ao consumo e a busca da homogeneização tornaram-se crescentemente presentes no contexto regional, para o qual a televisão passou a exercer um papel centralizador.

No movimento dialético, a vida urbana transgride reiteradamente a ordem, entrecruzando interesses históricos, estéticos e comunicacionais. De acordo com Canclini (2003), a permanente luta em prol da neutralização da mensagem ou da mudança de significado representa a expressão de conflitos entre as forças sociais, "entre o mercado, a história, o Estado, a publicidade e a luta popular". São pressões externas que se impõem sobre o campo da cultura popular, que se espacializa nas cidades brasileiras e latino-americanas. Tal espacialização encontra latência nas periferias e nos bairros populares.

Assim, a chamada "cultura urbana" vem sendo reestruturada ao longo do tempo, o que se percebe de forma bastante nítida na redefinição do próprio espaço público na medida em que são difundidas as tecnologias eletrônicas. 
Ocorre contemporaneamente uma espécie de "mediatização social", segundo Canclini (2003). Mediante este quadro, compreender o espaço de expressão cultural que se materializa nos bairros populares e nas periferias urbanas de uma forma geral se transforma num desafio comunicacional.

De acordo com Martin-Barbero (2001,p.281), são recosturadas "solidariedades de origem nacional ou de trabalho, o bairro inicia e entretece novas redes" que têm como campos sociais os espaços do cotidiano (os bares, a sinuca, o campo de futebol, dentre outros). Aqui, Barbero se encontra com Simmel ao pensar a forma pela qual são tecidas as relações solidárias da sociedade, percebendo os bairros populares como espaços nos quais os laços advindos das pequenas cidades se desfazem e se redefinem sob novas feições.

Yi-Fu Tuan $(1980,2006)$ aporta às reflexões sobre o espaço urbano os conceitos de topofilia e topofobia. Permite visualizar a relação dialética entre o temor despertado pelo espaço, quando um grupo social o define como espaço de violência (topofobia); por outro lado, a afetividade que a ele pode ser associada por seus moradores como espaço vivido (topofilia). Reforçando assim a indagação sobre o que são o espaço e o lugar, em termos de experiência humana. "Os espaços do homem refletem a qualidade dos seus sentidos e sua mentalidade" (TUAN, 2006, p.18). Desta feita, ratifica a idéia de que o espaço reside não apenas fora, mas também dentro do ser humano.

\section{Apontamentos finais}

A cidade vista como espaço que consolida a ação humana, recortada em lugares que expressam a cotidianidade dos seus moradores e enquanto expressão das formas sensíveis de organizar a vida constituiu o objeto de nossa digressão neste breve ensaio. $O$ apoio teórico do qual lançamos mão está inscrito nos campos de estudos da Geografia e da Sociologia. Estas duas ciências se interconectam no desafio contemporâneo que coloca a cultura e o espaço como objetos necessários de reflexão. 
Em consonância com a abordagem de teóricos das ciências sociais, tais como Georg Simmel, Norbert Elias, Nèstor Garcia Canclini e Jesus MartinBarbero, há um esforço da geografia humanista-cultural, que privilegia novas qualidades como subjetividade, intuição, sentimentos, experiências e simbolismos (KOZEL, 2007, p.118). Afastando-se de uma leitura lógico positivista do espaço filia-se às orientações teóricas da fenomenologia e do existencialismo, que percebem os indivíduos como agentes agregadores de pluralidade e complexidade ao espaço.

O espaço passa a ser entendido como "espaço vivido pelas experiências humanas, cada ser humano em sua individualidade. Por isso, contribuem para ressignificar categorias como a "paisagem" e o "lugar", bem como refletir sobre o que representam a objetividade e a subjetividade na geografia (TUAN,1983 Apud KOZEL 2007).

\footnotetext{
... A cidade de quem passa sem entrar é uma; é outra para quem é aprisionado e não sai mais dali; uma é a cidade à qual se chega pela primeira vez, outra é a que se abandona para nunca mais retornar; cada uma merece um nome diferente; talvez eu já tenha falado de Irene sob outros nomes; talvez eu só tenha falado de Irene (CALVINO, 1997, p. 115).
}

Na poesia de Quintana (2005) e Calvino (1997) está impressa a forma sintética de refletir sobre a realidade complexa da cidade. Realidade que vivemos e percebemos, ou, nem sempre. Mas também, onde guardamos nossos temores e amores mais íntimos que, por sua vez, nos vinculam ao lugar. E nos fazem reconstruí-lo em memória, quase sempre tão distinto do lugar seco e rígido, pelas linhas tortuosas que povoam nossas mentes, repletas de encontros e desencontros da vida.

\section{REFERÊNCIAS}

BENÉVOLO, Leonardo. A cidade e o arquiteto. Trad. Attílio Cancian. São Paulo: Ed. Perspectiva, 1991.

CALVINO, Ítalo. As Cidades Invisíveis. Trad. Diogo Mainardi. São Paulo: Cia das Letras, 1990.

CANCLINI, N.. Culturas Híbridas: estratégias para entrar e sair da modernidade. São Paulo: Edusp, 2003. 
COSTA, Simone P.. Apontamentos para uma leitura de Georg Simmel. In: Diálogos. Maringá, DH / UEM, v.3, n.3, p. 291-307, 1999.

DURHAN, Eunice. A dinâmica da cultura: ensaios de antropologia. São Paulo: Cosac Naify Editora, 2004.

ELIAS, Norbert. A condição Humana. Trad. Manoel Loureiro, São Paulo: Difel, 1985.

A Sociedade dos Indivíduos. Trad. Vera Ribeiro, Rio de Janeiro: Ed. Jorge Zahar, 1994.

Janeiro: Jorge Zahar, 1994.

O processo civilizador. Trad. Ruy Jungman. v.1, 2.ed. Rio de

ELIAS, N; SCOTSON, J. Os estabelecidos e os Outsiders: sociologia das relações de poder a partir de uma pequena comunidade. Rio de Janeiro: WVA, 2000.

FELÍCIO, Eguimar; ANJOS, Antônio Fernando dos. A periferia urbana em questão: um estudo socioespacial de sua formação. IN: Boletim Goiano de Geografia. v. 27, n. 02, Jan./Jun 2007.

KOZEL, Salete. Mapas Mentais - Uma Forma de Linguagem: Perspectivas Metodológicas. IN: KOZEL, Salete; SILVA, Josué da Costa; GIL FILHO, Sylvio Fausto.(Orgs). Da percepção e Cognição à representação: Reconstruções Teóricas da Geografia Cultural e Humanista. São Paulo: Terceira Margem; Curitiba: NEER, 2007.

HARVEY, David. Condição Pós-moderna. Uma pesquisa sobre as Origens da Mudança Cultural. São Paulo: Ed. Loyola, 1992.

. Espaços de Esperança. São Paulo: Ed. Loyola, 2004.

LE GOFF, Jacques. A História Nova. In: LE GOFF, Jacques; CHARTIER, Roger; REVEL, Jacques (orgs). A História Nova. Tradução de Eduardo Brandão. 5a edição, São Paulo: Martins Fontes, 2005.

LEFEBVRE, Henri. O Direito à Cidade. São Paulo: Ed. Moraes, 1991.

MARTíN-BARBERO, Jesus. Dos Meios às Mediações - Comunicação, Cultura e Hegemonia. Rio de Janeiro: Editora UFRJ, 2001.

MATHEWS, J.A. and Herbert, D. Unifying Geography - Common heritage, shared future. (Orgs.) London. New York. Oxfordshire: Routledge. 2004.

MORIN, Edgar. As cegueiras do conhecimento: o erro e a ilusão. In: Os Sete saberes necessários à educação do futuro. São Paulo: Cortez, Brasília, DF: UNESCO. 2000a.

Martins, Francisco Menezes \& Silva, Juremir Machado da (Orgs.). Para Navegar no século XXI - Tecnologias do Imaginário e Cibercultura. Porto Alegre: EDIPUCRS. 2000b.

QUINTANA, Mário. Apontamentos de História Sobrenatural. Rio de Janeiro: Globo, 2005. 
SANTOS, Milton. Metamorfoses do Espaço Habitado - fundamentos Teórico e metodológico da geografia. São Paulo: Hucitec, 1988.

Por uma Geografia Nova: Da crítica da geografia a uma

geografia crítica. São Paulo: Editora da Universidade de São Paulo, 2008.

SIMMEL, Georg. As Grandes Cidades e a Vida do Espírito (1903). Covilhã, Universidade da Beira Interior: Lusosofia Press, 2009.

. O Indívíduo e a Liberdade. In: SOUZA, Jessé e OELZE, Berthold. Simmel e a Modernidade. Brasília: UNB, 1998.

Sociologia. São Paulo: Ática, 1993.

TEDESCO, J. Carlos. Georg Simmel e as ambigüidades da modernidade. IN: Ciências Sociais, Unisinos, 43 (1): 57-67, Jan/abril, 2007.

TUAN, Yi-Fu. Topofilia: um estudo da percepção, atitudes e valores do meio ambiente. São Paulo: Difel, 1980.

VELHO, Gilberto. A grande cidade brasileira: sobre heterogeneidade e diversidade culturais. IN: Revista do Patrimônio Histórico e Artístico Nacional - MINc. Rio de Janeiro, nº 26, 1986. 